\title{
Quality of life can be part of the cure
}

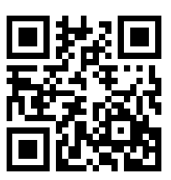

Though he had narrowly survived his first round of leukaemia chemotherapy, for Peter Paterson* (age 14) the tipping point in choosing to undergo another gruelling nine months of chemo was the fun he'd had with new friends suffering similar conditions on a recent wildlife safari camp.

Professor David Reynders, Manager of the Paediatric Oncology Unit at Steve Biko Hospital, believes his patient's ultimate treatment success was largely due to the rejuvenation he got from a Just Footprints Foundation camp held at Phiri Game Camp, part of the new 'Big Five' Dinokeng Game Reserve, 20 minutes' drive from Pretoria. Peter is one of 1550 children diagnosed with cancer, blood disorders and other lifethreatening illnesses, and/or infected with or affected by HIV, who've enjoyed what many describe as 'the adventure of their lives' at 32 camps held across the country over the past 4 years. Being one among the 100 new cases that each paediatric oncology unit countrywide handles on average annually with an average $65 \%$ cure rate - Peter found that his holiday camp was perfectly timed.

He'd recovered from his debilitating treatment, regained some strength and was in a 'holding pattern' of apparent remission. This let him take advantage of the carefully crafted camp programme, aimed at developing confidence and self-esteem in a nurturing environment that combines adventure, new skills development and just plain fun. The contrast between this and his traumatic recent treatment could not have been greater. As with every cancer treatment, each case is a complex web of decisions, and Peter's recovery and newly-acquired lust for life contributed strongly to his decision to 'try chemo again', this time successfully.

Reynders, who besides being Principal Specialist at Steve Biko and a senior lecturer at the University of Pretoria, heads the medical board of the Just Footprints Foundation, explained: 'The new trend is to get away from this concept of "cure at all costs" - we've broken ourselves from just pumping patients full of chemo, with the child just surviving and not necessarily living. We look at quality of life. They need to know that there is life after chemotherapy. Communicating that is vital.'

He firmly believes the camps contribute to treatment compliance. Many patients, especially adolescents, fall by the wayside

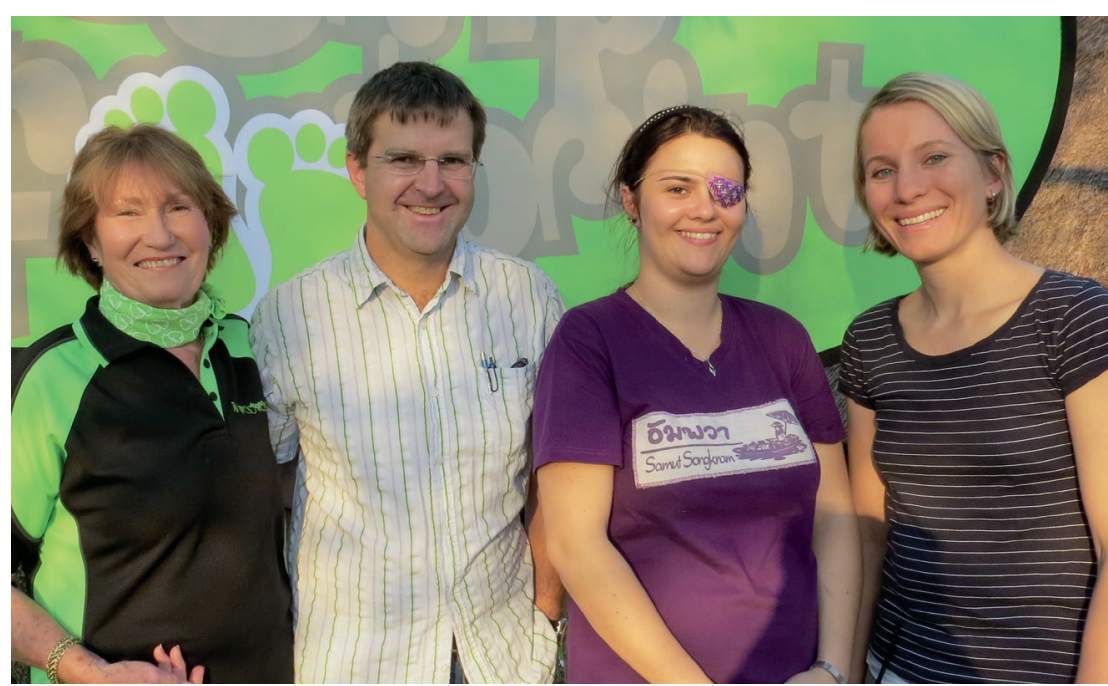

From left: Ane Buchner (Paediatrician and fellow in Paediatric Oncology), Professor David Reynders, Gail Mathews (Nurse) and Leoné Jooste, of the Just Footprints Foundation.

when the chemotherapy ride gets too rough. Lately, however, several teenagers are convincing their parents to let them continue or repeat therapy after enjoying a breakaway camp. 'They realise that though they've felt miserable, there is a time when it gets better,' Reynders explained. He cites a study from the similar United States 'SeriousFun Children's Network' summer camps model (founded by the late Hollywood actor Paul Newman) which showed clinical significance in dealing with post-traumatic stress disorder (PTSD) and high levels of satisfaction from friendships. 'These are hard scientific facts, though we've haven't done similar studies here - it's all anecdotal', he cautions.

\section{Palliation vital to care}

Some children who've gone on camps have subsequently succumbed to their illness, or died from the toxicity of their treatment. However, this emphasises the palliative value of the camps and underscores the underlying philosophy: quality of life, in addition to the hope of cure.

Leoné Jooste, Chairperson of the Just Footprints Foundation, is one of the pioneers of holiday camps for children with special needs and serious medical conditions in South Africa. She said the idea of a custom-designed and -built safari lodge was born after Paul Newman visited Botswana a decade ago. After the cancer-struck child of a close friend was excluded from a traditional American summer camp, Newman had used his influence and network of wealthy celebrity contacts to start the American 'Hole in the Wall' camps (run globally today as the SeriousFun Children's Network). He consulted with clinicians at Yale Medical school to develop a psycho-social camp model geared towards kids receiving treatment, between treatments or with special needs.

After the Botswana visit Jooste, a veteran of helping special needs and ill children, was roped in to identify kids to attend local camps. When that model evolved into environmental awareness camps for community-based, able-bodied children, Jooste refused to let go of the dream. She pulled together four well-known NGOs that work with seriously ill and disabled children to form the Just Footprints Foundation.

Today, the foundation sponsors camps on KwaZulu-Natal's South Coast (Hibberdene Children's Home), in Simon's Town (Rocklands Camp) and near Pretoria (Phiri Camp). They mainly draw cancer patients from local tertiary hospitals (Steve Biko and George Mukare hospitals in Pretoria and Chris Hani Baragwanath and Charlotte Maxeke hospitals in Johannesburg, Red Cross Children's Hospital in Cape Town, and Albert Luthuli Hospital and the Pietermaritzburg Hospitals Complex in KwaZulu-Natal). Cotlands, an HIV NGO near Turfontein, refers teenagers on antiretrovirals from their outreach communities in Somerset West and KwaZulu-Natal. The Childhood Cancer Foundation (CHOC) is also a major referral agency and founding partner.

To attend the camps, children must be older than 6 years, able to take care of themselves, have undergone no chemotherapy for at 
least a fortnight prior to attending a camp and have functioning immune systems and no obvious bleeding tendencies. Consent is required from both parents and the treating physician. Camp staff include a doctor, nurses and social workers with a ratio of one camp volunteer per two children. The American model includes high-level onsite facilities (including chemotherapy, blood transfusions, dialysis, lumbar punctures and other medical procedures), which Reynders and Jooste hope to emulate in the near future.

\section{Custom-built safari camp in the offing}

Most exciting, however, are plans for an ambitious, custom-built, R25 million 'fully green' development at Dinokeng. Jooste says the facility will host an eco-science discovery centre and be able to accommodate 100 children plus staff and volunteer caregivers. It will include a medical clinic, dining hall, kitchen and activity centre, swimming pools, and bungalows for staff, volunteers and campers. All these amenities will be disability-friendly and solar and geothermal heating and waste-water management will be integrated into the facility. The project is due for conceptual launch with architectural drawings this month.

As well as the camps, Jooste said the premises will also be rented out to schools or private organisations to help all children overcome the negative effects of modern- day 'nature-deprivation syndrome', whose main contributors are increasingly sedentary lifestyles and technological innovation.

Concluded Jooste, 'Our vision is to provide a special journey of life-changing experiences for each impaired child that will leave an imprint on their hearts, with hope for the future. In turn, each child will leave an imprint of their footprint at the camp in support of those who follow.'

${ }^{\star}$ Not his real name.

\section{Chris Bateman}

chrisb@hmpg.co.za

S Afr Med J 2013;103(11):820-821.

DOI:10.7196/SAMJ.7562 